\title{
Convective Heat Transfer and Friction Factor Characteristics in Internally Threaded Tube with Constant Heat Flux for $\mathrm{Al}_{2} \mathrm{O}_{3} /$ Water Nanofluid
}

\author{
Pankaj N. Shrirao ${ }^{1}$, Sagar S. Gaddamwar ${ }^{2}$, Pravin R. Ingole ${ }^{3}$ \\ ${ }^{\mathbf{1}}$ Assistant Professor (Mechanical Engineering), Jawaharlal Darda Institute of Engineering and Technology, Yavatmal, India \\ ${ }^{2}$ Assistant Professor (Mechanical Engineering), Jawaharlal Darda Institute of Engineering and Technology, Yavatmal, India \\ ${ }^{3}$ Assistant Professor (Mechanical Engineering), Jawaharlal Darda Institute of Engineering and Technology, Yavatmal, India
}

\begin{abstract}
This work presents an experimental study on the mean Nusselt number, friction factor and thermal enhancement factor characteristics in a circular plain tube and internally threaded tube under uniform wall heat flux boundary conditions for pure water and $\mathrm{Al}_{2} \mathrm{O}_{3}$ nanofluid as working fluid. The effects of the internal threads and nanofluid on the Nusselt number and the friction factor are determined in a circular tube with a fully developed turbulent flow for the Reynolds number in the range between 3000 and 25000. The horizontal tube with $1200 \mathrm{~mm}$ length was used as the test section having internal knuckle threads of pitch 12 mm. Firstly the experiments were performed on plain tube and internally threaded tube with pure water as working fluid and secondly with nanofluid consisted of $\mathrm{Al}_{2} \mathrm{O}_{3}$ nanoparticles with an average diameter of $12 \mathrm{~nm}$ dispersed in water having volume fraction of $1.5 \%$. The heat transfer and pressure drop data obtained was compared with the data obtained from a plain tube under similar geometric and flow conditions. It is observed that at all Reynolds number, the Nusselt number and thermal performance increases for a tube with internal threads and nanofluid as compared with plain tube and pure water. These are because of increase in thermal diffusivity of nanofluid and also because of strength and intensity of vortices ejected from the internal threads. Subsequently an empirical correlation is also formulated to match with experimental results with $\pm 7 \%$ and $\pm 8 \%$, variation respectively for Nusselt number and friction factor.
\end{abstract}

Keywords: Nanofluid, Internal threads, Turbulent flow and heat transfer characteristics.

\section{Introduction}

The convective heat transfer can be enhanced passively by changing the flow geometry, boundary conditions, or by enhancing the thermal conductivity of the fluid. Researchers tried to increase the heat transfer rate by increasing the thermal conductivity of the fluid. As a new research and technology frontier, nanofluids are used to enhance heat transfer. Nanofluids are engineered colloids which are made of a base fluid and nanoparticles (1-100) nm. The advantages of nanofluids are: (1) higher thermal conductivity than that predicted by currently available macroscopic models, (2) excellent stability, and (3) little penalty due to an enhancement in pressure drop and pipe wall erosion experienced by suspensions of micrometer or millimeter particles [1]. Such advantages of nanofluid offer important benefits for numerous applications in many fields such as petrochemical, refining, electronic, transportation, medicine, heating, and air- conditioning.

Fotukian and Esfahany [2] investigated experimentally turbulent convective heat transfer of dilute $\gamma-\mathrm{Al}_{2} \mathrm{O}_{3} /$ water inside circular tubes. The nanofluid $\gamma-\mathrm{Al}_{2} \mathrm{O}_{3}$ /water with dilute loading of $0.03 \%, 0.054 \%, 0.135 \%$ were studied. The Reynolds number was varied from 6000 to 31000 . The experimental results indicated that addition of small amount of nanoparticles to pure water improves the heat transfer performance significantly. The maximum value of $48 \%$ increase in the heat transfer coefficient compared to pure water for $0.054 \%$ volume concentration at Reynolds number of 10000 was observed. Increasing the particle concentration did not show much heat transfer enhancement in the turbulent region. The ratio of convective heat transfer coefficient of nanofluid to that of pure water decreases with the Reynolds number. The pressure drop of the nanofluid with $0.135 \%$ volume concentration with showed $30 \%$ increase at Reynolds number of 20000 compared to pure water.

Pak and Cho [3] studied experimentally the heat performance of $\mathrm{Al}_{2} \mathrm{O}_{3}$ and $\mathrm{TiO}_{2}$ nanoparticles dispersed in water flowing in horizontal circular tube. Alumina and Titanium dioxide $\left(\mathrm{TiO}_{2}\right)$ nanoparticles with diameter $13 \mathrm{~nm}$ and $27 \mathrm{~nm}$ respectively were used in their study. They found that the Nusselt number of nanofluid increased with increases the Reynolds number as well as volume fraction. However they still found that the convective heat transfer coefficient of nanofluid with $3 \%$ by vol nanoparticles was $12 \%$ lower that of pure water at agaves Reynolds number. This may cause the nanofluid to have larger viscosity than that of pure water, especially at high particle volume fraction.

Hojjat et al. [4] investigated experimentally the forced convective heat transfer using dispersing $\gamma-\mathrm{Al}_{2} \mathrm{O}_{3}, \mathrm{CuO}$, and $\mathrm{TiO}_{2}$ nanoparticles in an aqueous solution of carboxymethyl cellulose (CMC). Their experimental apparatus included a uniformly heated circular tube under turbulent flow conditions passing through these nanofluids. Their results showed that the local and average heat transfer coefficients of nanofluids were larger than those of the base fluid. A new correlation was therefore proposed for the prediction of the Nusselt number of non-Newtonian nanofluids as a function of the Reynolds and the Prandtl numbers. 


\section{International Journal of Science and Research (IJSR) \\ ISSN (Online): 2319-7064}

Index Copernicus Value (2013): 6.14 | Impact Factor (2014): 5.611

$Y u$ et al. [5] measured the heat transfer rates in the turbulent flow of $\mathrm{SiC} /$ water nanofluid consisting of a volume concentration of $3.7 \%$ with $170 \mathrm{~nm}$ silicon carbide particles. Heat transfer coefficient increase of 50-60\% above the base fluid water was obtained when compared on the basis of constant Reynolds number. Heat transfer mechanisms that involve particle interactions are believed for heat transfer enhancement.

Sajadi [6] investigated experimentally turbulent heat transfer behaviour of $\mathrm{TiO}_{2}$ /water nanofluid in a circular pipe with volume fraction of nanoparticles in the base fluid was in the range (0.05-0.25\%) and Reynolds number range (5000$30000)$. The results indicated that addition of small amounts of nanoparticles to the base fluid augmented heat transfer remarkably. The measurements also showed that the pressure drop of nanofluid was slightly higher than that of the base fluid and increased with increasing the volume concentration. Experimental results have been compared with the existing correlations for nanofluid convective heat transfer coefficient in turbulent regime.

Another alternative method to enhance heat transfer is to insert twisted tape into a core tube. This approach induces secondary recirculation to the axial flow, leading to an increase in tangential and radial turbulent fluctuation and thus reducing a thickness of the boundary layer. Using nanofluid together with twisted taped for heat transfer enhancement was reported in numerous research works such as twisted tape inserts with $\mathrm{Al}_{2} \mathrm{O}_{3}$ /water nanofluid [7] and [8], helical twist tape inserts with $\mathrm{Al}_{2} \mathrm{O}_{3}$ /water nanofluid [9], twisted tape with alternate axis inserts with $\mathrm{CuO} /$ water nanofluid [10], twisted tape inserts with $\mathrm{CuO} /$ water nanofluid in corrugated tube [11], dual twisted tape inserts with $\mathrm{CuO} /$ water nanofluid in micro-fin tube [12], helical screw tape inserts with $\mathrm{Al}_{2} \mathrm{O}_{3}$ /water nanofluids [13], helical screw tape inserts using $\mathrm{CuO}$ /water nanofluids [14], and propeller inserts with $\mathrm{TiO}_{2} /$ water nanofluid [15].

Heat transfer enhancement by inserting twisted tape is always escorted by the increase of flow resistance. The proper modification of twisted tape is a key approach to achieve a reasonable tradeoff between the increases of heat transfer rate and flow resistance. The driving force for this research work is to reduce the flow resistance due to these inserts by increasing the heat transfer rate. The aim of this study is to investigate experimentally flow and convective heat transfer characteristics of water-based nanofluid flowing through internally threaded tube of $35 \mathrm{~mm}$ inner diameter. The horizontal internally threaded tube with $1200 \mathrm{~mm}$ length is used as the test section.

\section{Experimental Work}

An experimental rig is built to study the convective heat transfer and flow characteristics of pure water and nanofluid flowing in a plain tube and internally threaded tube. The heat transfer test section is a straight brass tube with an inner diameter of $35 \mathrm{~mm}$ and a length of $1200 \mathrm{~mm}$. Thermocouples are mounted at different places of the heat transfer test section to measure the wall temperatures and the fluid bulk temperatures. To obtain a constant heat-flux boundary condition, the heat transfer test section is heated electrically by a DC power supply capable of delivering a maximum of $3.5 \mathrm{~kW}$. A Rotameter is used to measure the flow through the test section. The pressure drop of the heat transfer test tube is measured with manometer under an isothermal condition. The test section is isolated thermally from its upstream and downstream sections by plastic bushings to minimize the heat loss resulting from axial heat conduction. In order to minimize the heat loss from the test section to the ambient, the whole test section is thermally insulated. The hydrodynamic entry section is long enough to accomplish fully developed flow at the entrance of the heat transfer test section.

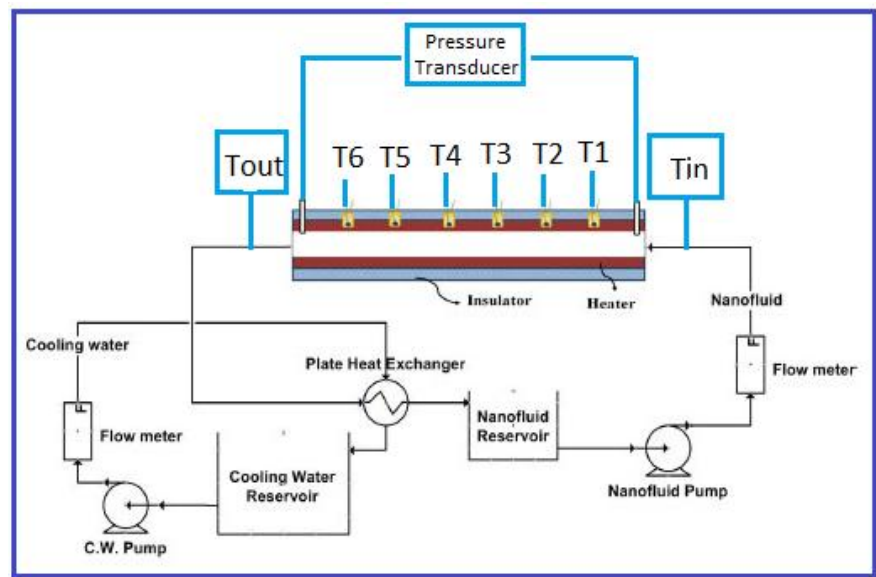

Figure 1: Schematic diagram of the experimental apparatus

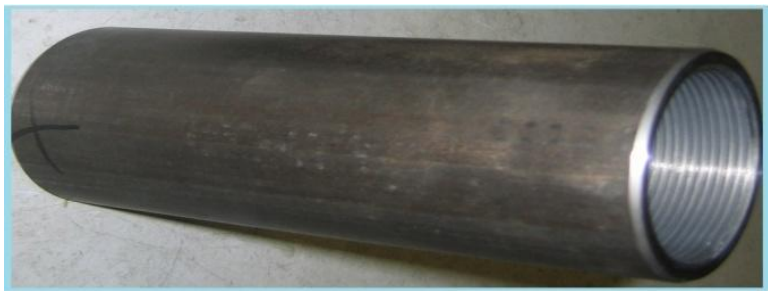

Figure 2: Internally threaded tube used as test section

Firstly the experiments were performed on plain tube with pure water and $\mathrm{Al}_{2} \mathrm{O}_{3}$ water based nanofluid as working fluid. Secondly the experiments were performed on internally threaded tube with pure water and $\mathrm{Al}_{2} \mathrm{O}_{3}$ water based nanofluid as working fluid. The heat transfer and pressure drop data obtained was compared with the data obtained from a plain tube under similar geometric and flow conditions. The properties of fluids for the flow and heat transfer evaluations are based on the average temperature of tube wall and inlet-outlet fluid temperatures.

Before measuring the convective heat transfer coefficient of nanofluid, the experimental system was calibrated by comparing the measured Nusselt numbers of water at the fully developed turbulent flow with the calculated values using the Dittus-Boelter equation. The good coincidence between the experimental results and the calculated values shows that the precision of the experimental system is relatively high. 


\section{International Journal of Science and Research (IJSR) \\ ISSN (Online): 2319-7064 \\ Index Copernicus Value (2013): 6.14 | Impact Factor (2014): 5.611}

Thus, it can be concluded that the results from the present experimental facility are reliable. Thus, the facility was employed for further investigation with internal threads and nanofluid.

\section{Data reduction}

The data reduction of the measured results is summarized in the following procedures:

$$
\begin{gathered}
\mathrm{T}_{\mathrm{s}}=\left(\mathrm{T}_{1}+\mathrm{T}_{2}+\mathrm{T}_{3}+\mathrm{T}_{4}+\mathrm{T}_{5}+\mathrm{T}_{6}\right) / 6 \\
\mathrm{~T}_{\mathrm{b}}=(\mathrm{Tin}+\mathrm{Tout}) / 2
\end{gathered}
$$

Velocity of flow, $\mathrm{V}=\mathrm{Q} / \mathrm{A}$

$\mathrm{A}=$ convective heat transfer area $\left(\Pi^{*} \mathrm{D}^{*} \mathrm{~L}\right)$

$$
\operatorname{Re}=\rho \mathrm{VD} / \mu
$$

$\mathrm{D}=$ inner diameter of pipe

$\mathrm{L}=$ Length of pipe

$$
\mathrm{Q}=\mathrm{Qc}+\mathrm{Qr}
$$$$
\mathrm{Q}=\mathrm{m} \mathrm{C}_{\mathrm{p}}\left(\mathrm{T}_{1}-\mathrm{T}_{5}\right)
$$

$\mathrm{m}=$ mass flow of water

$$
\mathrm{Qr}=\sigma \mathrm{A} \varepsilon\left(\mathrm{T}_{\mathrm{s}}{ }^{4}-\mathrm{T}_{\mathrm{b}}{ }^{4}\right)
$$

$$
\mathrm{h}=(\mathrm{Q}-\mathrm{Qr}) /\left(\mathrm{A}\left(\mathrm{T}_{\mathrm{s}}-\mathrm{T}_{\mathrm{b}}\right)\right.
$$

Experimental Nusselt number is calculated by

$$
\mathrm{Nu}=\mathrm{h} \mathrm{D} / \mathrm{K}
$$

Nusselt numbers calculated from the experimental data for plain tube were compared with the correlation recommended by Dittus-Boelter

$$
\mathrm{Nu}=0.023 \operatorname{Re}^{0.8} \operatorname{Pr}^{0.4}
$$

Equation gives theoretical Nusselt number.

In straight pipe lengths, Pressure drop $(\Delta \mathrm{P})$ can be calculated using the Darcy Equation

$$
\Delta P_{\text {Friction }}=\frac{\text { f. } L_{\text {Pipe }}}{d_{\text {Pipe }}} \frac{\rho \cdot u^{2}}{2}
$$

$\mathrm{f}=$ Darcy friction factor

Friction factor correlation

Correlation of Petukhov

$\mathrm{f}=(0.790 \ln \mathrm{Re}-1.64)^{-2}$ for $3000 \leq \mathrm{Re} \leq 5 \times 10^{6}$

\section{Results and Discussions}

Experimentally determined Nusselt number values for plain horizontal circular tube (without internal threads) with pure water as working fluid are compared with Dittus-Boelter correlation.

Fig. 3 shows the comparison between Nusselt numbers obtained experimentally and by using Dittus-Boelter equation for plain tube. It is observed that the value of $\mathrm{Nu}$ (experimental) is less than $\mathrm{Nu}$ (Dittus-Boelter). Actual heat carried away by water passing through the test section is the combination of convective and radiative heat transfers. As the heat transferred by convection alone is considered while performing experimental and numerical calculations, it can be expected that $\mathrm{Nu}$ (experimental) is less than $\mathrm{Nu}$ (DittusBoelter).

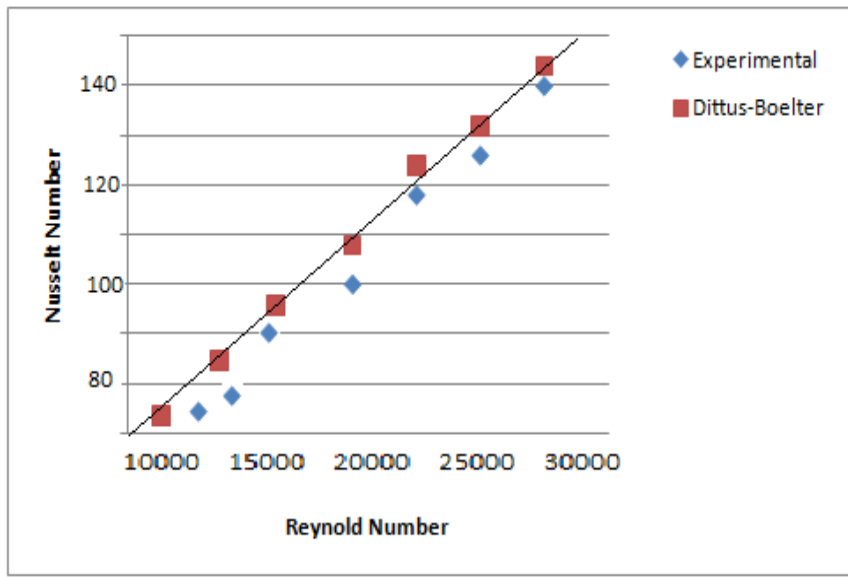

Figure 3: Comparison between the measured results and the calculated values of pure water in plain tube

As shown in Figure 4 the Nusselt number increases with increases the Reynold number in pure water as well as in $\mathrm{Al}_{2} \mathrm{O}_{3}$ nanofluid solution. It can be clearly seen that the Nusselt number of $\mathrm{Al}_{2} \mathrm{O}_{3}$ nanofluid solution is higher than that of the pure water at a given Reynold number. The increase in Nusselt number is because of the fact that the he suspended $\mathrm{Al}_{2} \mathrm{O}_{3}$ nanoparticles increases the thermal conductivity of the two phase mixture. Furthermore, disorganized movement of these particles accelerated energy exchange process in the fluid. It is also observed that Nusselt number of $\mathrm{Al}_{2} \mathrm{O}_{3}$ nanofluid solution in threaded tube is higher than that of in plain tube. This is because of increase in swirling motion in threaded tube which in turn responsible for heat transfer enhancement.

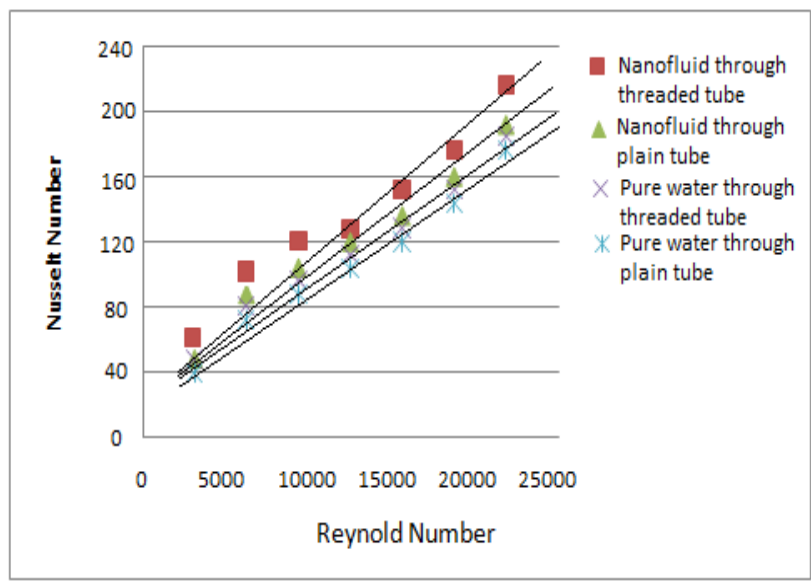

Figure 4: Comparison Nusselt number of pure water and nanofluid solution as a function of Reynolds number in plain and threaded tube

Figure 5 shows the pressure drop of pure water and $\mathrm{Al}_{2} \mathrm{O}_{3}$ nanofluid solution measured by pressure transducer. The pressure drop of the nanofluid is slightly increased compared with that of the pure water, because an increase in the friction loss is caused by suspension of $\mathrm{Al}_{2} \mathrm{O}_{3}$ nanoparticles in the pure fluid. On the other hand, pressure drop of $\mathrm{Al}_{2} \mathrm{O}_{3}$ nanofluid solution in threaded tube are greater than in circular tube. This phenomena is caused because of swirling motion created by threaded tube. 


\section{International Journal of Science and Research (IJSR) \\ ISSN (Online): 2319-7064}

Index Copernicus Value (2013): 6.14 | Impact Factor (2014): 5.611

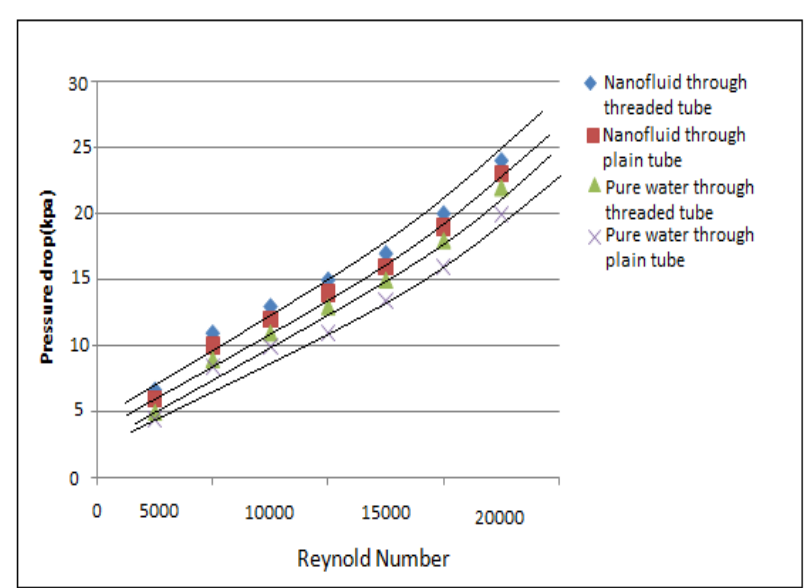

Figure 5: Pressure drop of pure water and nanofluid in pain and threaded tube

Figure 6 shows the variation of friction factor Vs Reynolds number pure water and $\mathrm{Al}_{2} \mathrm{O}_{3}$ nanofluid solution in plain and threaded tube. It is observed that the friction factor decreases with increase in Reynolds number for pure water and $\mathrm{Al}_{2} \mathrm{O}_{3}$ nanofluid solution in plain and threaded tube. The friction factor for nanofluid through threaded tube is more than that for plain tube. This is because of advancement in swirling motion due to artificial turbulence created by threaded tube.

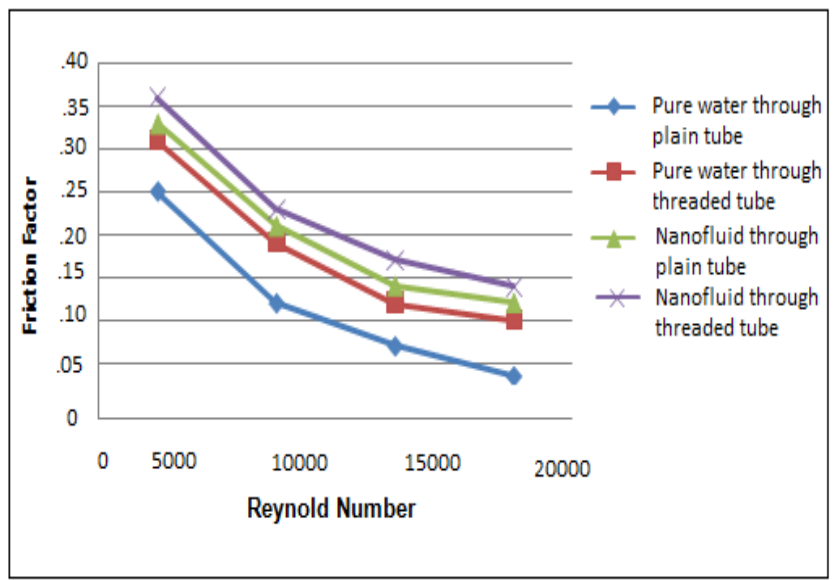

Figure 6: Comparison Friction factor of pure water and nanofluid solution as a function of Reynolds number in plain and threaded tube

\section{Conclusion}

The convective heat transfer and pressure drop characteristics that occur with internal threads and nanoparticles for a fluid flowing in a circular tube in the turbulent flow regime was experimentally investigated. The results are summarized follows:

- Convective heat transfer of the $\mathrm{Al}_{2} \mathrm{O}_{3}$-water nanofluid is significantly higher than those of the pure water.

- The pressure drop of the $\mathrm{Al}_{2} \mathrm{O}_{3}$-water nanofluid is approximately the same as those of pure water in the given conditions.

- The Pressure drop of internally threaded tube tends to increase slightly compared with plain tube.

- The convective heat transfer coefficient of the $\mathrm{Al}_{2} \mathrm{O}_{3}$-water nanofluid flowing in internally threaded tube increases by up to $21 \%$ compared with that of pure water flowing in a plain tube.

- The obtained results indicated that internal threads induced swirling-flow which played an important role in improving fluid mixing and heat transfer enhancement.

\section{References}

[1] Choi, S.U.S. "Enhancing thermal conductivity of fluids with nanoparticles", In: D.A. Siginer and H.P Wang (Eds), Developments and Applications of NonNewtonian Flows, ASME FED, 231/MD, 66, pp. 99105, 1995.

[2] S. M. Fotukian, M.Nasr Esfahany, "Experimental investigation of turbulent convective heat transfer heat transfer of dilute $\gamma$-Al2O3/water nanofluid inside a circular tubes", International Journal of Heat and Fluid Flow 31 (2010) 606- 612.

[3] Pak B. C., Cho Y. I., "Hydrodynamic and heat transfer study of dispersed fluids with submicron metallic oxide particles", Experimental Heat Transfer 11 pp.151-170, (1998).

[4] Hojjat, M.; Etemad, S. Gh.; Bagheri, R.; Thibault. J. "Convective heat transfer of non-Newtonian nanofluids through a uniformly heated circular tube", Int. J. Therm. Sci., 2011, 50, 525-531.

[5] Yu W., France D., Smith D., Singh D., Timofeeva E., Routbort J., "Heattransfer to a silicon carbide/water nanofluid", International Journal of Heat Mass Transfer 2009; 2:3606-12.

[6] Sajadi A. R., Kazemi M. H., "Investigation of turbulent convective heat transfer and pressure drop of TiO2/water nanofluid in circular tube", International Communications in Heat and Mass Transfer, 38, (2011), 1474-1478.

[7] K.V. Sharma, L. Syam Sundar, P.K. Sarma, "Estimation of heat transfer coefficient and friction factor in the transition flow with low volume concentration of $\mathrm{Al}_{2} \mathrm{O}_{3}$ nanofluid flowing in a circular tube and with twisted tape insert", Int. Commun. Heat Mass Transf., 36 (2009), pp. 503-507

[8] L. Syam Sundar, K.V. Sharma "Turbulent heat transfer and friction factor of $\mathrm{Al}_{2} \mathrm{O}_{3}$ nanofluid in circular tube with twisted tape inserts", Int. J. Heat Mass Transf., 53 (2010), pp. 1409-1416

[9] G. Pathipakka, P. Sivashanmugam "Heat transfer behaviour of nanofluids in a uniformly heated circular tube fitted with helical inserts in laminar flow", Superlattices Microstruct., 47 (2010), pp. 349-360.

$[10] \mathrm{K}$. Wongcharee, S. Eiamsa-ard "Enhancement of heat transfer using $\mathrm{CuO} /$ water nanofluid and twisted tape with alternate axis", Int. Commun. Heat Mass Transf., 38 (2011), pp. 742-748.

[11]K. Wongcharee, S. Eiamsa-ard "Heat transfer enhancement by using $\mathrm{CuO} /$ water nanofluid in corrugated tube equipped with twisted tape", Int. Commun. Heat Mass Transf., 39 (2012), pp. 251-257.

[12] S. Eiamsa-ard, K. Wongcharee "Single-phase heat transfer of $\mathrm{CuO} /$ water nanofluids in micro-fin tube equipped with dual twisted-tapes", Int. Commun. Heat Mass Transf., 39 (2012), pp. 1453-1459. 
[13] S. Suresh, K.P. Venkitaraj, P. Selvakumar "Comparative study on thermal performance of helical screw tape inserts in laminar flow using $\mathrm{Al}_{2} \mathrm{O}_{3} /$ water and $\mathrm{CuO} /$ water nanofluids", Superlattices Microstruct., 49 (2011), pp. 608-622.

[14] S. Suresh, K.P. Venkitaraj, P. Selvakumar, M. Chandrasekar "A comparison of thermal characteristics of $\mathrm{Al}_{2} \mathrm{O}_{3} /$ water and $\mathrm{CuO} /$ water nanofluids in transition flow through a straight circular duct fitted with helical screw tape inserts", Exp. Therm. Fluid Sci., 39 (2012), pp. 37-44.

[15] V.T. Perarasu, M. Arivazhagan, P. Sivashanmugam "Heat transfer of $\mathrm{TiO}_{2}$ /water nanofluid in a coiled agitated vessel with propeller", J. Hydrodyn. Ser. B, 24 (2012), pp. 942-950.

\section{Author Profile}

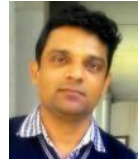

Dr. Pankaj N. Shrirao is Assistant Professor (Mechanical Engineering) in Jawaharlal Darda Institute of Engineering and Technology, Yavatmal, India. He has completed his Doctoral research work from Government College of Engineering Amravati and awarded Ph.D. from Sant Gadge Baba Amravati University, Amravati. He holds his Bachelor Degree in Mechanical Engineering and Master Degree in Thermal Power with total 11 years of experience. He has published 15 papers in international journals and conferences. His areas of interest are heat transfer and IC Engine.

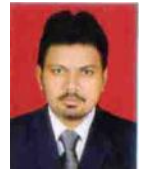

Sagar S. Gaddamwar is Assistant Professor (Mechanical Engineering) in Jawaharlal Darda Institute of Engineering and Technology, Yavatmal, India. He has completed his Bachelor Degree in Mechanical Engineering and Master Degree in Heat Powerl Engineering from RTMNU, Nagpur with total 04 years of experience. He has published 06 papers in international journals and conferences. His areas of interest are Heat transfer and IC Engine.

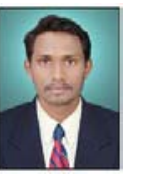

Pravin R. Ingole is Assistant Professor (Mechanical Engineering) in Jawaharlal Darda Institute of Engineering and Technology, Yavatmal, India. He has completed his Bachelor Degree in Mechanical Engineering and Master Degree in CAD/CAM from RTMNU, Nagpur with total 02 years of experience. He has published 07 papers in international journals and conferences. His areas of interest are Robotics and Fatigue failure. 